\title{
Multi-drug resistance profiles and the genetic features of Acinetobacter baumannii isolates from Bolivia
}

\author{
Bruno S. Lopes ${ }^{1}$, Lucía Gallego ${ }^{2}$, Sebastian G. B. Amyes ${ }^{1}$ \\ ${ }^{1}$ Medical Microbiology, The University of Edinburgh, Edinburgh, United Kingdom \\ ${ }^{2}$ Departmento Inmunología, Microbiología y Parasitología, Facultad de Medicina y Odontología, Universidad del \\ País Vasco, Campus de Bizkaia, Leioa, Spain
}

\begin{abstract}
Introduction: Acinetobacter baumannii is opportunistic in debilitated hospitalised patients. Because information from some South American countries was previously lacking, this study examined the emergence of multi-resistant $A$. baumannii in three hospitals in Cochabamba, Bolivia, from 2008 to 2009.

Methodology: Multiplex PCR was used to identify the main resistance genes in 15 multi-resistant $A$. baumannii isolates. RT-PCR was used to measure gene expression. The genetic environment of these genes was also analysed by PCR amplification and sequencing. Minimum inhibitory concentrations were determined for key antibiotics and some were determined in the presence of an efflux pump inhibitor, 1-(1napthylmethyl) piperazine.

Results: Fourteen strains were found to be multi-resistant. Each strain was found to have the bla $a_{\text {OXA-58 }}$ gene with the ISAba3-like element upstream, responsible for over-expression of the latter and subsequent carbapenem resistance. Similarly, ISAba1, upstream of the $b l a_{\mathrm{ADC}}$ gene caused over-expression of the latter and cephalosporin resistance; mutations in the gyrA(Ser83 to Leu) and parC (Ser- 80 to Phe) genes were commensurate with fluoroquinolone resistance. In addition, the ade $A$, adeB efflux genes were over-expressed. All 15 isolates were positive for at least two aminoglycoside resistance genes.

Conclusion: This is one of the first reports analyzing the multi-drug resistance profile of $A$. baumannii strains isolated in Bolivia and shows that the over-expression of thebla $a_{\mathrm{OXA}-58}, b l a_{\mathrm{ADC}}$ and efflux genes together with aminoglycoside modifying enzymes and mutations in DNA topoisomerases are responsible for the multi-resistance of the bacteria and the subsequent difficulty in treating infections caused by them.
\end{abstract}

Key words: Acinetobacter baumannii; insertion sequences; beta-lactamases; carbapenems; gene; environment

J Infect Dev Ctries 2013; 7(4):323-328. doi:10.3855/jidc.2711

(Received 26 April 2012 - Accepted 16 June 2012)

Copyright $(02013$ Lopes et al. This is an open-access article distributed under the Creative Commons Attribution License, which permits unrestricted use, distribution, and reproduction in any medium, provided the original work is properly cited.

\section{Introduction}

Acinetobacter baumannii is a pathogenic bacterium responsible for a wide range of infections such as septicaemia, meningitis, pneumonia and urinary tract infections and is one of the most important Gram-negative pathogens causing infections in immuno-compromised patients [1]. Acinetobacter baumannii has been considered the paradigm of multiresistant bacteria because of emerging multi-drug resistance to various antimicrobial agents [2], notably mutations in gyrA and parC genes that confer fluoroquinolone resistance and activation of the aminoglycoside inactivating enzymes [2,3,4]. Betalactam antibiotics (mainly carbapenems) are now the first drug of choice to treat these microorganisms; however, in the last decade, resistance to carbapenems has appeared in hospitals worldwide owing to the production of beta-lactamases, changes in permeability, increase in efflux, and modification of the affinity of penicillin-binding proteins (PBPs) in these bacteria $[2,3]$.

Transposable elements also play a major role in gene expression. They are generally tightly regulated and exercise their role in a strategic manner [5]. Insertion sequences carrying promoters are often responsible for driving the expression of the downstream antibiotic resistance gene, often leading to the over-expression of the gene, and making the bacterium resistant to various antibiotics [6].

A. baumannii is considered an emerging pathogen but very few reports are available from developing countries in Latin America on the mechanisms responsible for carbapenem resistance. In this study we analysed the factors involved in antibiotic resistance in various clinical strains isolated from three major hospitals in Cochabamba, Bolivia. We also 
investigated the genetic environments responsible for carbapenem and ceftazidine resistance as well as the mutations that confer resistance to fluoroquinolones.

\section{Methodology}

Fifteen isolates thought to have a multi-resistant profile were selected for this study. The isolates were obtained from three different hospitals in Cochabamba in 2008-2009 [Table]. The isolates were identified as $A$. baumannii by PCR amplification and sequencing of the $b l a_{\text {OXA-51-like [7] }}$ and $r p o B$ genes [8].

\section{Antimicrobial susceptibility testing}

All the isolates were tested for their susceptibility to imipenem (IPM), meropenem (MEM), ceftazidime (CAZ), ciprofloxacin (CIP), and gentamicin (CN). Minimum inhibitory concentrations (MICs) were determined by the agar double dilution method according to the British Society for Antimicrobial Chemotherapy (BSAC) methodology [9]. The MICs of ciprofloxacin and gentamicin were also determined in the presence of an efflux pump inhibitor 1-(1napthylmethyl), piperazine (NMP) $(100 \mathrm{mg} / \mathrm{L})$. The results were interpreted according to BSAC guidelines [9]. The reference strains used for MIC testing were Escherichia coli NCTC 10418, P. aeruginosa ATCC 10662, and S. aureus NCTC 6571.

Screening for antimicrobial resistance genes of the bla $_{O X A}$ family

All the isolates were screened for the presence of genes of the $b l a_{\text {OXA-23-like, }} b l a_{\text {OXA-40-like, }} b l a_{\text {OXA-51-like, }}$ bla $a_{\text {OXA-58-like }}$ and bla $_{\text {OXA-143-like families by multiplex }}$ PCR described by Higgins and colleagues [10]. The primers described by Héritier et al. [11] were used for the amplification and sequencing of the $b l a_{\text {OXA-58-like }}$ gene. The primer SM2, described by Poirel and Nordmann [12], was used in combination with walk58-R [13] for amplification and sequencing of the region upstream of the $b l a_{\text {OXA-58-like }}$ gene.

\section{Screening for the disruption of the carO gene}

PCR amplification for the insertions causing disruption of the carO gene $(29 \mathrm{kDa}$ OMP) was also completed for all the isolates using primers as described by Mussi et al. [14].

Screening for the presence of aminoglycoside resistance genes

A multiplex PCR was performed for the screening of aminoglycoside resistance genes as described earlier by Noppe-Leclercq et al. [4]. PCR was also performed to check for the presence of the armA gene and other rRNA methylases such as $r m t A, r m t B$ and $r m t C$ using primers described by Yamane et al. [15]. The $r m t D$ gene screening was completed using primers described by Doi et al. [16].

Screening for the presence of other antimicrobial determinants

PCR arrays were performed for the identification of bla $a_{\mathrm{TEM}}, b l a_{\mathrm{SHV}}, b l a_{\mathrm{PER}-2}$ and $b l a_{\mathrm{CTX}-\mathrm{M}-2}$ enzymes using primers described by Celenza et al. [17]. Amplification of the $b l a_{\mathrm{VEB}}$ and $b l a_{\mathrm{GES}}$ genes was performed as described by Moubareck et al. [18].

Analysis of the genetic environment of the bla $\mathrm{a}_{A D C}$ gene

Primers FU (5'-GCGCCGTGAATTCTTAAGTG3') and RU (5'-AGCCATACCTGGCACATCAT-3') were used for amplification of the intergenic region upstream of the $b l a_{\mathrm{ADC}}$ gene. Primers FD (5'CAGCTTATGCTGTGCTGGAT-3') and RD (5'GAGCTGCCATATTGGGAAGA-3') were used to amplify the intergenic region downstream of the $b l a_{\mathrm{ADC}}$ gene.

Analysis of the quinolone resistance-determining region (QRDR)

PCR assays as described by Valentine and colleagues [3] were used for the amplification of the QRDRs of the gyrA and parC genes. The gene fragments were sequenced and checked for specific amino acid changes.

Analysis of the adeABC and adeRS genes involved in efflux

PCR was performed to check for the presence of adeABC and adeRS genes. The intergenic regions of adeRS were amplified using the primers adeRF (5'GCA TTA CGC ATA GGT GCA GA-3') and adeSR (5'-GAG GTC GCC GTG ACT AAT TT-3'). The primers adeRA (5'-TCA CGG GAG TCT GAG CTT TT-3') and adeAB (5'-AAT AGG CGC TCG AAC TGT TG-3') were used to check for any insertions between the adeRA genes. The primers adeAF (5'CGC AAG TCG GAG GTA TCA TT-3') and adeAR (5'- TAT ACC TGA GGC TCG CCA CT-3') were used for the amplification of adeA, while the primers adeBF (5'-CCCTAATCAAGGACGTATGC-3') and adeBR (5'-TAG AGT GCA GCC AAG ACA AG- 3') were used for the amplification of the $a d e B$ gene. The primers adeCF (5'-AGCCTGCAATTACATCTCAT 3') and adeCR (5'-TGGCACTTCACTATCAATAC- 
3') were used to check for the presence of the adeC outer membrane gene.

\section{Analysis of gene expression}

Expression of the $b l a_{\mathrm{ADC}}, b l a_{\mathrm{OXA}-58-\mathrm{like}}$, ade $A, a d e B$ and ade $C$ genes was studied by RT-PCR. The primers for the bla $a_{\mathrm{ADC}}$ gene were those defined by Ruiz et al. [19] and those used for bla OXA-58-like gene expression were the multiplex primers described by Woodford et al. [20]. The adeAF and adeAR, adeBF and adeBR, and adeCF and adeCR primers were used to determine ade $A$, adeB, and ade $C$ expression. Total RNA was extracted from isolates in the exponential growth phase using the RiboPure Bacteria kit (Ambion, Paisley, United Kingdom) and treated with the DNase I provided. cDNA was synthesised from 100ng of RNA using the Access quick RT-PCR system kit (Promega, Southampton, United Kingdom). The PCR products were quantified using the Bio-Rad Quantity One Software 4.6.1 (Bio-Rad, Hemel Hempstead, United Kingdom). 16S-rRNA gene primers as described by Lin et al. [21] were used for normalization. The results were confirmed three times and were based on the average of the mean increase or decrease of the individual strains.

\section{Results}

Isolates were confirmed as $A$. baumannii by $b a_{\text {OXA-51-like }}($ Table) and $r p o B$ gene PCR. All strains except isolate 2 were resistant to one or more antibiotics tested. They had previously been confirmed to be clonally related according to their PFGE profiles [22].

The table shows the MIC values of IPM, MEM, $\mathrm{CAZ}, \mathrm{CIP}, \mathrm{CIP}+\mathrm{NMP}, \mathrm{CN}$ and $\mathrm{CN}+\mathrm{NMP}$ in each individual isolate. It shows that all the strains except two were multi-resistant. The MIC of gentamicin did not change upon the addition of NMP; however, NMP did give a two- to four-fold decrease in isolates resistant to CIP, suggesting that efflux pumps partially contribute to resistance in these isolates.

The table identifies the specific $b{ }_{1} a_{\text {OXA-51-like }}$ gene in each isolate; none of them had insertion sequences upstream of the bla $a_{\text {OXA-51-like gene. All isolates except }}$ number 2 were positive for the bla $a_{\text {OXA-58-like }}$ gene determined by multiplex PCR. Sequencing of the $b l a_{\text {OXA-58-like }}$ gene revealed no nucleotide changes. The primers SM-2 and walk-58-R detected the insertion of an ISAba3-like structure $17 \mathrm{bp}$ upstream of the bla $a_{\text {OXA- }}$ ${ }_{58}$ gene. Putative promoters with -35 (TTTATC) and 10 (TTTCTT) motifs were detected in the ISAba3-like element. The promoters had previously been identified by Poirel and Nordman [11] and correlate with the high MICs of carbapenems resistance in these isolates (Table). The ISAba3-like element had a single codon change at position 25 (GAT to AAT) which led to an aspartate to asparagine amino acid change; however, this but did not affect its activity. The role of the insertion sequence is supported by the observation that

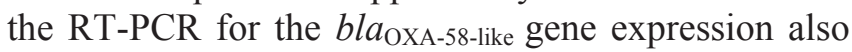
recorded high levels of expression in the isolates positive for the $b l a_{\text {OXA-58-like }}$ gene (Table). The $b l a_{\text {OXA- }}$ 58 -like gene was found to be present on the $40 \mathrm{~kb}$ plasmid in all strains resistant to carbapenems except isolate 2 (which was carbapenem sensitive).

The $\operatorname{car} O$ gene fragment was not disrupted by any insertion element (as indicated earlier by Mussi et al. [14]) and thus did not contribute to reduced carbapenem susceptibility.

Multiplex PCR revealed that all isolates except isolate 2 were positive for two aminoglycoside resistance enzymes, the $a a c\left(6^{\prime}\right)-I b$ and $a p h\left(3^{\prime}\right)-V I$. As reviewed by Shaw et al. [23] the aac(6')-Ib class of aminoglycoside inactivating enzymes has been shown to confer resistance to to bramycin, dibekacin, amikacin, 5-episisomicin, netilmicin, 2'-Nethylnetilmicin, and sisomicin, whereas the $\operatorname{aph}\left(3^{\prime}\right)-V I$ group of enzymes is characterized by resistance to kanamycin, neomycin, paromomycin, ribostamycin, butirosin, amikacin, isepamicin and gentamicin. Isolate 2 , on the other hand, was positive for three enzymes: $a p h\left(3^{\prime}\right)-I a$, which confers resistance to various aminoglycosides including gentamicin; $a a c(3)-I a$, responsible for resistance to gentamicin and fortimicin; and ant(2')-Ia, which hydrolyzes tobramycin, dibekacin, sisomicin, kanamycin and gentamicin. In each strain these combinations of enzymes contribute to the high MIC of gentamicin. The MICs of gentamicin did not decrease after the addition of NMP, indicating that resistance to gentamicin may not be efflux mediated. Aminoglycoside resistance is common in Acinetobacter spp and often derives from inactivation of the antibiotic by the specific modifying enzymes described above [24]. The PCR assays for the rRNA methylase genes such as armA, rmtA, rmtB, rmtC, and $r m t D$ were all negative.

PCR performed for the identification of $b l a_{\mathrm{SHV}}$, $b l a_{\mathrm{PER}-2}, b l a_{\mathrm{CTX}-\mathrm{M}-2}, \quad b l a_{\mathrm{VEB}}$ and $b l a_{\mathrm{GES}}$ genes were negative. All isolates had the bla $a_{\mathrm{TEM}-1}$ gene which was amplified and sequenced.

ISAbal was found to be present upstream of the $b l a_{\mathrm{ADC}}$ gene in all the strains except isolate 2; the latter had a low MIC of ceftazidime. There was no insertion 
Table. In vitro activities of antibiotics, levels of gene expression and the mutations in QRDR's in the $A$. baumannii clinical isolates

\begin{tabular}{|c|c|c|c|c|c|c|c|c|c|c|c|c|c|c|c|c|}
\hline \multirow[b]{2}{*}{ No } & \multirow[b]{2}{*}{ Hospital } & \multicolumn{8}{|c|}{$\mathrm{MIC}(\mathrm{mg} / \mathrm{L})$} & \multicolumn{5}{|c|}{ The level of gene expression* } & \multirow{2}{*}{$\begin{array}{l}\text { gyr } A \\
\text { ser83 }\end{array}$} & \multirow{2}{*}{$\begin{array}{l}\text { parC } \\
\text { ser80 }\end{array}$} \\
\hline & & IPM & MEM & $\mathrm{CN}$ & $\mathrm{CN}+\mathrm{NMP}$ & CIP & $\mathrm{CIP}+\mathrm{NMP}$ & CAZ & 51-like & 58 & $b l a_{\mathrm{ADC}}$ & adeA & adeB & adeC & & \\
\hline 1 & GBJ & 8 & 2 & 128 & 128 & 256 & 64 & 128 & 65 & 14 & 15 & 28 & 29 & 15 & Leu & Phe \\
\hline 2 & $\mathrm{~V}$ & 0.25 & 0.5 & 256 & 256 & 1 & 1 & 16 & 66 & - & 5 & 20 & 18 & 14 & Ser & Ser \\
\hline 3 & V & 8 & 2 & $>256$ & 256 & 256 & 64 & 128 & 65 & 14 & 14 & 31 & 31 & 14 & Leu & Phe \\
\hline 4 & $\mathrm{~V}$ & 8 & 2 & 256 & 256 & 256 & 64 & 128 & 65 & 14 & 15 & 25 & 29 & 14 & Leu & Phe \\
\hline 5 & V & 8 & 2 & 64 & 64 & 128 & 32 & 128 & 65 & 15 & 15 & 27 & 29 & 13 & Leu & Phe \\
\hline 6 & GBJ & 16 & 4 & 64 & 64 & 128 & 32 & 128 & 65 & 14 & 16 & 26 & 28 & 13 & Leu & Phe \\
\hline 7 & $\mathrm{~V}$ & 8 & 2 & 128 & 128 & 256 & 64 & 128 & 65 & 15 & 15 & 27 & 30 & 11 & Leu & Phe \\
\hline 8 & V & 8 & 2 & 64 & 64 & 256 & 64 & 128 & 65 & 15 & 15 & 26 & 29 & 14 & Leu & Phe \\
\hline 9 & $\mathrm{CO}$ & 8 & 2 & $>256$ & 256 & $>256$ & 64 & 128 & 65 & 14 & 14 & 31 & 36 & 15 & Leu & Phe \\
\hline 10 & $\mathrm{~V}$ & 8 & 2 & 64 & 64 & 128 & 32 & 128 & 65 & 14 & 15 & 26 & 28 & 15 & Leu & Phe \\
\hline 11 & $\mathrm{CO}$ & 8 & 2 & 128 & 128 & 256 & 64 & 128 & 65 & 15 & 14 & 27 & 29 & 14 & Leu & Phe \\
\hline 12 & V & 16 & 2 & 128 & 128 & 256 & 64 & 128 & 65 & 14 & 15 & 27 & 27 & 13 & Leu & Phe \\
\hline 13 & V & 8 & 2 & 256 & 256 & 128 & 64 & 128 & 65 & 15 & 14 & 28 & 27 & 15 & Leu & Phe \\
\hline 14 & V & 8 & 2 & 256 & 256 & 128 & 64 & 128 & 65 & 15 & 14 & 27 & 28 & 17 & Leu & Phe \\
\hline 15 & $\mathrm{~V}$ & 8 & 2 & 256 & 256 & 128 & 64 & 128 & 65 & 14 & 15 & 28 & 28 & 15 & Leu & Phe \\
\hline
\end{tabular}

GBJ = Gastroenterológico Boliviano-Japonés, $\mathrm{V}=$ Viedma, $\mathrm{CO}=$ Clínica Olivos

$*$ = Relative gene expression was determined by RT PCR and quantified by Bio-Rad quantity I software.

$+=$ present

- = absent

$\mathrm{IPM}=$ imipenem, $\mathrm{CN}$ = gentamicin, $\mathrm{CIP}=$ ciprofloxacin, $\mathrm{CAZ}=$ ceftazidime, $\mathrm{NMP}=1-(1$-napthylmethyl $)$ piperazine 
detected downstream of the $b l a_{\mathrm{ADC}}$ gene in any of the isolates. Expression of the $b l a_{\mathrm{ADC}}$ gene in the strains was identified by the high MIC values of ceftazidime and confirmed by RT-PCR.

The intergenic regions of adeRS were amplified using the primers adeRF (5'-GCA TTA CGC ATA GGT GCA GA-3') and adeSR (5'-GAG GTC GCC GTG ACT AAT TT-3'); these amplified a 790bp product, indicating that there was no insertion. The primers adeRA (5'-TCA CGG GAG TCT GAG CTT TT-3') and adeAB (5'- AAT AGG CGC TCG AAC TGT TG-3') amplified a product of $929 \mathrm{bp}$, indicating there was no insertion between these two genes. Ruzin et al. [25] previously reported that ISAbalmay contribute to the expression of the efflux genes. The primers adeCF (5'-AGC CTG CCA TTA CAT CTC AT-3') and adeCR (5'-TGG CAC TTC ACT ATC AAT AC-3') detected the presence of the adeC gene. Because the strains had a very high MIC of ciprofloxacin, which decreased after the addition of NMP (Table), we hypothesized that the efflux pump genes would be highly expressed. RT-PCR for analysis of the adeA (encoding for the membrane fusion protein) and the $a d e B$ (encoding the RNDtransporter) genes revealed that both the genes were highly expressed as they are co-transcribed (Table). The adeC (encoding the outer membrane protein) was not as highly expressed as ade $A$ and $a d e B$; the reason may that its expression is not necessary to confer resistance [26] as alternative outer membrane proteins can be used by bacteria to export substrates for effluxing any poisons or antibiotics. We checked further for mutations in gyrA and parC as well as the antibiotic determinants responsible for ciprofloxacin resistance in these isolates. Sequencing of the gyrA and $\operatorname{par} C$ genes revealed Ser-83 to Leu and Ser- 80 to Phe amino acid changes in isolates resistant to ciprofloxacin. Resistance to ciprofloxacin was mainlydue to target site mutations in the gyrA and $\operatorname{par} C$ with a small contribution by the efflux pumps.

\section{Discussion}

This work analyzed the genetic environment and the multi-drug resistance profile of $A$. baumannii isolated in Cochabamba, Bolivia, as there are few surveys that study the multi-drug resistant profile of clinical isolates in Bolivia. Multi-drug resistance is certainly of great concern. A previous study by Celenza et al. [17] reported no carbapenem resistance in any of the isolates studied. The current investigation showed that carbapenem resistance is manifested largely by the presence of the OXA-58 carbapenemase. Surprisingly, the PCR results for the $b l a_{\mathrm{PER}-2}$ and $b l a_{\text {СTX-M-2 }}$ genes were negative. These results contradict those of a study conducted in Bolivia in 2006 by Celenza et al. [17] in which the presence of these genes was reported. We therefore conclude that the presence of ISAbal upstream of the $b l a_{\mathrm{ADC}}$ gene has substituted the $b l a_{\text {PER-2 }}$ and $b l a_{\text {CTX-M-2genes to }}$ confer high levels of resistance to ceftazidime and provide a stable mechanism of cephalosporin resistance to the bacterium.

The presence of the $b l a_{\text {OXA-58 }}$ gene has been observed in other Latin American countries. These results support the worldwide spread of the $b l a_{\text {OXA-58 }}$ gene, one of the major causes of carbapenem resistance [27]. Ciprofloxacin resistance in the isolates was largely determined by target site mutations with partial contribution by the efflux pumps. Each strain had at least two aminoglycoside modifying enzymes which together contributed to high levels of resistance to gentamicin. The high proportion of strains with resistance genes to the major groups of antibiotics used to control $A$. baumannii found in this study is of great concern as clonal spread has been observed among the three hospitals where these isolates were isolated. Mobilization of bla $a_{\text {OXA-58-like }}$ carbapenemase genes has often been found to be associated with insertion sequences or transposons, and the potential of spread via plasmid motors is very high. The OXA23-like and OXA-58-like enzymes have been found in Brazil, Venezuela, Colombia, Chile, Bolivia and Argentina; however, OXA-58-like enzymes are most frequently identified in South America [28]. The spread of plasmid-borne carbapenemases can occur inter- or intra-specifically in hospital environments, so it is important to develop control strategies to prevent infections caused by carbapenem-resistant $A$. baumannii. This strategy should help in the prevention of nosocomial spread of infections, especially among immuno-compromised patients.

\section{Acknowledgements}

We are grateful to Dr. Zulema Bustamante, Dpto. de Bioquímica y Farmacia, Universidad Mayor de San Simón (Cochabamba, Bolivia), for the gift of $A$. baumannii clinical strains.

Funding: BSL was funded by the University of Edinburgh Overseas Research scholarship. A part of this project was funded by an RA0119 MRC grant. LG was funded by a grant from Vicerrectorado de Investigación de la Universidad del Pais Vasco (Plan de movilidad de investigadores).

\section{References}

1. Bergogne-Bérézin E, Towner KJ (1996) Acinetobacter spp. as nosocomial pathogens: microbiological, clinical, and epidemiological features. Clin Microbiol Rev 9: 148-165. 
2. Vila J, Martí S, Sánchez-Céspedes J (2007) Porins, efflux pumps and multidrug resistancein Acinetobacter baumannii. J Antimicrob Chemother 59: 1210-1215.

3. Valentine SC, Contreras D, Tan S, Real LJ, Chu S, Xu HH (2008) Phenotypic and molecular characterization of Acinetobacter baumannii clinical isolates from nosocomial outbreaks in Los Angeles County, California. Antimicrob Agents and Chemother 46: 2499-2507.

4. Noppe-Leclercq I, Wallet F, Haentjens S, Courcol R, Simonet M (1999) PCR detection of aminoglycoside resistance genes: a rapid molecular typing method for Acinetobacter baumannii. Res Microbiol 150: 317-322.

5. Mugnier PD, Poirel L, Nordmann P (2009) Functional analysis of insertion sequence ISAbal, responsible for genomic plasticity of Acinetobacter baumannii. JBacteriol 191: 2414-2418.

6. Corvec S, Poirel L, Naas T, Drugeon H, Nordmann P (2007) Genetics and expression of the carbapenem-hydrolyzing oxacillinase gene bla OXA-23 $_{2}$ in Acinetobacter baumannii. Antimicrob Agents Chemother 51: 1530-1533.

7. Héritier C, Poirel L, Fournier PE, Claverie JM, Raoult D, Nordmann P (2005) Characterization of the naturally occurring oxacillinase of Acinetobacter baumannii. Antimicrob Agents Chemother 49: 4174-4179.

8. La Scola B, Gundi VAKB, Khamis A, Raoult D (2006) Sequencing of the rpoBgene and flanking spacers for molecular identification of Acinetobacter Species. J Clin Micro 44: 827-832.

9. Andrews JM, and the British Society for Antimicrobial Chemotherapy (BSAC) (2010) Methods for Antimicrobial Susceptibility Testing Version 9.1. Birmingham.

10. Higgins PG, Lehmann M, SeifertH (2010) Inclusion of OXA143 primers in a multiplex polymerase chain reaction (PCR) for genes encoding prevalent OXA carbapenemases in Acinetobacter spp. Int J Antimicrob Agents 35: 305.

11. Héritier C, Dubouix A, Poirel L, Marty N, Nordmann P (2005) A nosocomial outbreak of Acinetobacter baumannii isolates expressing the carbapenem-hydrolysing oxacillinase OXA-58. J Antimicrob Chemother 55: 115-118.

12. Poirel L and Nordmann P (2006) Genetic structures at the origin of acquisition andexpression of the carbapenemhydrolyzing oxacillinase gene $b l a_{\mathrm{OXA}-58}$ in Acinetobacter baumannii. Antimicrob Agents Chemother 50: 1442-1448.

13. Lopes BS, Evans BA, Amyes SGB (2012) The disruption of the $b l a_{\text {OXA-51-like }}$ gene by ISAbal6 and the activation of the $b l a_{\text {OXA-58 }}$ gene leading to carbapenem resistance in Acinetobacter baumannii Ab244. J Antimicrob Chemother 67: 59-63.

14. Mussi MA, Limansky AS, Viale AM (2005) Acquisition of resistance to carbapenems in multidrug-resistant clinical strains of Acinetobacter baumannii: Natural insertional inactivation of a gene encoding a member of a novel family of $\beta$-Barrel Outer Membrane Proteins. Antimicrob Agents Chemother 49: 1432-1440.

15. Yamane K, Wachino J, Suzuki S, Shibata N, Kato H, Shibayama K, Kimura K, Kai K, Ishikawa S, Ozawa Y, Konda T, Arakawa Y (2007) 16S rRNAmethylase-producing, gram-negative pathogens, Japan. Emerg Infect Dis 13: 642646.

16. Doi Y, Ghilardi AC, Adams J, de Oliveira Garcia D, Paterson DL (2007) High prevalence of metallo-beta-lactamase and 16S rRNAmethylase coproduction among imipenem-resistant
Pseudomonas aeruginosa isolates in Brazil. Antimicrob Agents Chemother 51: 3388-3390.

17. Celenza G, Pellegrini C, Caccamo M, Segatore B, Amicosante G, Perilli M (2006) Spread of bla $a_{\text {CTX-M-type }}$ and bla $a_{\text {PER-2 }} \beta$-lactamase genes in clinical isolates from Bolivian hospitals. J Antimicrob Chemother 57: 975-978.

18. Moubareck C, Brémont S, Conroy MC, Courvalin P, Lambert T (2009) GES-11, a novel integron-associated GES variant in Acinetobacter baumannii. Antimicrob Agents Chemother 53: 3579-3581.

19. Ruiz M, Marti S, Fernandez-Cuenca F, Pascual A, Vila J (2007) Prevalence of ISAba1 in epidemiologically unrelated Acinetobacter baumannii clinical isolates. FEMS Microbiol Lett 274: 63-66

20. Woodford N, Ellington MJ, Coelho JM, Turton JF, Ward ME, Brown S, Amyes SG, Livermore DM (2006) Multiplex PCR for genes encoding prevalent OXA carbapenemases in Acinetobacter spp. Int J Antimicrob Agents 27: 351-353.

21. Lin L, Ling BD, Li XZ (2009) Distribution of the multidrug efflux pump genes, ade $\mathrm{ABC}$, adeDE and adeIJK, and class 1 integron genes in multiple-antimicrobial-resistant clinical isolates of Acinetobacter baumannii-Acinetobacter calcoaceticus complex. Int J Antimicrob Agents 33: 27-32.

22. Sevillano E, Fernandez E, Bustamante Z, Zabalaga S, Rosales I, Umaran A, Gallego L (2012) Emergence and Clonal Dissemination of Carbapenem-Hydrolysing OXA-58producing Acinetobacter baumannii isolates in Bolivia. J Med Micro 61: 80-84.

23. Shaw KJ, Rather PN, Hare RS, Miller GH (1993) Molecular genetics of aminoglycoside resistance genes and familial relationships of the aminoglycoside-modifying enzymes. Microbiol Rev 57: 138-163.

24. Magnet S, Courvalin P, Lambert $T$ (2001) Resistancenodulation-cell division-type efflux pump involved in aminoglycoside resistance in Acinetobacter baumannii strain BM4454. Antimicrob Agents Chemother 45: 3375-3380.

25. Ruzin A, Keeney D, Bradford PA (2007) AdeABC multidrug efflux pump is associated with decreased susceptibility to tigecycline in Acinetobacter calcoaceticus-Acinetobacter baumannii complex. J Antimicrob Chemother59: 1001-1004.

26. Marchand I, Damier-Piolle L, Courvalin P, Lambert T (2004) Expression of the RND-Type efflux pump AdeABC in Acinetobacter baumannii is regulated by the AdeRS twocomponent system. Antimicrob Agents Chemother 48: 32983304.

27. Coelho J, Woodford N, Afzal-Shah M, Livermore D (2006) Occurrence of OXA-58-like carbapenemases in Acinetobacter spp. collected over 10 years in three continents. Antimicrob Agents Chemother 50: 756-758.

28. Opazo A, Domínguez M, Bello H, Amyes SG, GonzálezRocha G (2012) OXA-type carbapenemases in Acinetobacter baumannii in South America. J Infect Dev Ctries 6: 311-316.

\section{Corresponding author}

Professor S. G. B. Amyes

Medical Microbiology, University of Edinburgh

Chancellor's Building, 49 Little France Crescent

Edinburgh EH16 4SB Scotland

Telephone: 01312426652

Fax: 01312426611

Email:s.g.b.amyes@ed.ac.uk

Conflict of interests: No conflict of interests is declared. 